\title{
Educational Significance of Games in Community Summer Trusteeship: An Ethnographic Study
}

\author{
Jiali Zhang ${ }^{1, *}$, Cheng $\mathrm{He}^{1}$ and Yanqiang Chen ${ }^{2}$ \\ ${ }^{1}$ School of Education (Teachers college), Guangzhou University, Gunagdong, Guangzhou, 510006, China \\ ${ }^{2}$ Longxiang Social Work Service Center, Longgang District, Gunagdong, Shenzhen, 518118, China \\ *Corresponding author. Email: 2112008009@e.gzhu.edu.cn
}

\begin{abstract}
Summer childcare has become a difficult problem for many dual-income families. In order to solve this problem, the Chinese government strongly advocates that communities undertake the responsibility of summer childcare for children. Under this background, this paper uses ethnographic research method to conduct field investigation on the summer trusteeship work of Pingshan Community in Pingshan District, Shenzhen. In this article we focus on one of the children's game segments, and use Game-based learning analysis model to analyse the educational significance of the games carried out in community summer childcare for children in emotion, cognition, behaviour and social culture, hoping to provide reference for the game design and practice of community summer childcare.
\end{abstract}

Keywords: game, summer childcare, ethnographic study, education, child development

\section{INTRODUCTION}

Children are naturally fond of games, just as Frobel said: The game is the highest stage of children's development, people's purest essence and inner thoughts are developed and expressed in the game. Games bringing their own incentive system (Hidi \& Renninger,2006; Rotgans \& Schmidt, 2011), is a symbolic social activity (Nicolopoulou, 1993), which can promote children's cognition development (Piaget, 1962; Deloache, 1987; Homer \& Hayward, 2008; Mayer, 2014), enrich children's emotional experience (Landry et al., 2013), influence children's behaviour (Zahyah, 2015) and social participation (Vygotsky, 1978). Electronic games are highly addictive and easily endanger children's eyesight and physical development, so the games referred to in this paper are biased towards the actual interactive games of real people, excluding electronic games.

The summer vacation in primary school usually lasts 2-3 months, which is equivalent to half a semester. Summer vacation is a golden period for children to develop their hobbies, strengthen their health and broaden their knowledge. On the contrary, if children's holidays are not arranged properly, it will increase the possibility of children suffering from chronic diseases and mental health problems [1]. However, the "difficult nursing" of children in summer holiday has become a global phenomenon-level social problem. For example, in China, especially in Shenzhen, which is famous for its busyness, it is difficult for parents to accompany their children for a long time in summer vacation, so quite a few children are unattended in summer vacation. In addition, the qualifications of the summer hosting institution in the free market are mixed, the service content and nursing quality are lack of supervision, and the phenomenon of collecting high custody fees is endless. This phenomenon has caused many parents' "summer anxiety" [2]. The difficulty of children's summer nursing is has become a national phenomenonlevel social problem in China [3].

In order to ensure children's safety during summer vacation and promote children's harmonious development, many governments had issued relevant policies to improve the quality of summer trusteeship. In April, 2021, the United States amended the Child Care and Development Block Grant Act promulgated in 1990 by inserting "as well as before- and after-school and summer care for schoolage children" after "services", striking "high-quality", "high-quality and inclusive", and supporting working parents in making their own decisions regarding the child care services that best suit their family's needs [4]. In July 2021, the General Office of the Ministry of Education of China formed the document Notice on Supporting Exploration of Summer Trusteeship Services, encouraging schools and communities to actively undertake summer trusteeship services for school-age children.

This paper discussed the educational significance of games carried out in Pingshan Community Summer Care Centre, which is beneficial to enrich the theory and practice of children's summer care and promote the development of children's personality and sociality.

\section{RESEARCH METHOD}

In terms of research methods, this paper chooses the ethnography of qualitative research and the game-based interactive analysis modelThis paper will focus on a fragment of "Design Home Game"and use the game-based interactive analysis model to analyse the educational 
significance in four dimensions. The theoretical framework of the study is shown in Table 1.

Table 1. Research theoretical framework

\begin{tabular}{|c|c|c|}
\hline \multirow{7}{*}{ Research methods } & $\begin{array}{c}\text { Ethnography of } \\
\text { qualitative } \\
\text { research }\end{array}$ & $\begin{array}{c}\text { Participatory } \\
\text { observation }\end{array}$ \\
\cline { 3 - 3 } & $\begin{array}{c}\text { Body sensory } \\
\text { observation }\end{array}$ \\
\cline { 3 - 3 } & & Faithful record \\
\cline { 3 - 3 } & $\begin{array}{c}\text { Affective } \\
\text { analysis }\end{array}$ \\
\cline { 3 - 3 } & $\begin{array}{c}\text { Cognitive } \\
\text { learning } \\
\text { analysis model }\end{array}$ & $\begin{array}{c}\text { Behavior } \\
\text { analysis }\end{array}$ \\
\cline { 3 - 3 } & & $\begin{array}{c}\text { Socio-cultural } \\
\text { analysis }\end{array}$ \\
\hline
\end{tabular}

\subsection{Ethnography of Qualitative Research}

The researchers personally went through the summer trusteeship as volunteers and used participatory observation method to observe what happened at that time with the help of body senses while interacting with the research object and made live recording without interfering with the normal activities. At the end of the day's trusteeship course, researchers got some image materials and physical materials from the propagandists of the summer trusteeship class. Finally, with the help of daytime observation and recording files, the researcher sorted out the research diary and archived it in the evening. During the study period, researchers made 9 participatory observations.

\subsection{Game-based Learning Analysis Model}

The theoretical framework of this study refers to the interactive model of learner activities (Domagk, Schwartz, $\&$ Plass, 2010) and the discussion on game participation based on this model (Jan, Bruce, \& Charles, 2015). The original interactive model of leaner activities distinguishes three different types of learners' participation in learning activities: cognitive participation, emotional participation and behavioral participation [6]. On the basis of this model, Jan et al. paid more attention to social and cultural participation. The whole framework of the analysis data in this paper is the version supplemented by Jan et al., which named Game-based learning model. Researchers used this model to analyse the educational influence of games in community summer care as a special learning activity on children from the four dimensions of cognition, emotion, behavior and social culture.

\section{RESEARCH PROCESS}

\subsection{Practice Overview}

In this section, I choose to pay special attention to a segment of "Design Home Game", because I think this piece contains a lot of fluctuations in children's cognition, emotion and behaviour when they participate in games. Participants' observation was carried out in the Party-Mass Service Center of Pingshan Community in Shenzhen. We spent about three days a week in the service centre to participate in the volunteer activities of the summer trusteeship classs as teachers. At the same time, we spent about one month in the service centre with 16 primary school students from grade three to grade six and three other volunteers. We will use the word participatory observation to describe the time I spent as a researcher in Pingshan Community Summer Trusteeship institution. See Table 2 for the contents of "Design Home Game".

\subsection{Practice Records and Results Based on Ethnographic Research Methods}

Today, on July 13th, 2021, we went to Pingshan District Party-mass Service Centre with two other volunteers for the second time to participate in summer trusteeship volunteer service. The theme of this volunteer activity was Chinese tutoring, but Xing Yan, a social worker, told us in advance that all the children's Chinese summer homework had been done, so what we needed to do is to prepare Chinese games instead of tutoring the children's Chinese summer homework. 26 A4 papers with printed contents, 3 scissors, and some lollipops were used.

Table 2. Part of the game "Design Home Game"

\begin{tabular}{|c|c|}
\hline \multicolumn{2}{|c|}{ Classification } \\
\hline Room & Item \\
\hline \multirow{4}{*}{ bedroom } & bed \\
\hline & pillow \\
\hline & sheet \\
\hline & $\ldots \ldots$ \\
\hline \multirow{4}{*}{ living room } & air conditioner \\
\hline & dining table \\
\hline & sofa \\
\hline & $\ldots \ldots$ \\
\hline \multirow{4}{*}{ kitchen } & kitchen knife \\
\hline & Chopping board \\
\hline & Rice cooker \\
\hline & $\ldots \ldots$ \\
\hline \multirow{4}{*}{ study } & pencil \\
\hline & ruler \\
\hline & dictionary \\
\hline & $\ldots \ldots$ \\
\hline \multirow{5}{*}{ bathroom } & Shower Gel \\
\hline & hair dryer \\
\hline & toothbrush \\
\hline & Toothpaste \\
\hline & ...... \\
\hline
\end{tabular}

The first game was "Design Home Game". Volunteers gave the list of common items in their homes and the list of rooms with different functions to social workers, and printed them in triplicate on A4 paper, then cut the list of 
items into small strips and disrupt the order of the strips. Divided the children into three groups and told them what they should do is to put the "items" represented by the slips on the corresponding "room" paper. Game props are shown in Fig. 1.

The first round was a simulated game so that children could fully understand the rules of the game. Before the host volunteers shouted out that the game starts, all children must raise their hands in the air and wait until they hear the instructions to start the game. After the team members put all the "items" in the corresponding "rooms", they went to hand in the air again and shouted "Task Achievement", and then entered the link of group mutual evaluation. The group with the highest accuracy rate and the shortest time is the winner, and the volunteers will give each team member a lollipop as a reward.

When the host volunteers explained the rules of the game, I found that some children kept moving and fiddling with notes, which seemed to be preparing for victory in advance. However, the host volunteer soon discovered this behaviour, and he said: "The notes of each group are the same number and different order, with five 'room' paper and 24 'items' notes. After each group getting the notes, you should check them, and hand them to the right-hand group. After exchanging, you can start to compete for the championship after hearing me say 'Game Start'." Interestingly, when the children heard these words, the children in the lower grades had not reacted, and the children in the fifth and sixth grades had begun to disturb the notes that had been secretly sorted out before, and shouted to the children in the lower grades to do the same. As a result, when all the children understood that the "game props" in their hands are for their competitors, not their own groups, they all took actions to create difficulties for their opponents--disarrange the notes. At the same time, the host volunteers reconfirmed that all the children understood the rules of the game, and then divided tasks with two other volunteers, each of whom was responsible for judging a group's results. Then, the simulation game began.

Vocabulary, knowledge of common sense, and teamwork are keys to success in this game. For example, the Chinese character "zhen" in the kitchen utensils "zhenban", which means "chopping block" is unknown to many children in grade three, so they need to ask the children in senior grades so that they can classify it as "kitchen" quickly. Setting up simulation links can minimize the influence of knowledge differences on game results and increase the fairness of the game. It can also improve children's unified understanding of rules and reduce disputes over game results.

During the game, with the encouragement of candy and victory, children were enthusiastic, all of them devoted themselves to the game, and the children in the same group could help each other even though they didn't know each other before. At the end of the competition, the host announced that the first group that completed the Design Home Game task would receive an extra five points, and then two members from each group would score the other two groups. 5 points will be deducted for each misplaced item. Volunteers recorded the scores of each group and decided the winner based on the total score. Each member of the winning group was happy to receive a lollipop, while the other groups couldn't hide their disappointment. Seeing this, the host comforted them and said, "If you don't win, don't be discouraged. There will be another chance. Now, why don't we think about why the second team wins? "

As soon as the question was raised, the children had a heated discussion and finally drew the conclusion that the reasons for the winning group's victory were the clearest task allocation and the most tacit cooperation. Fig. 2 shows the game process.

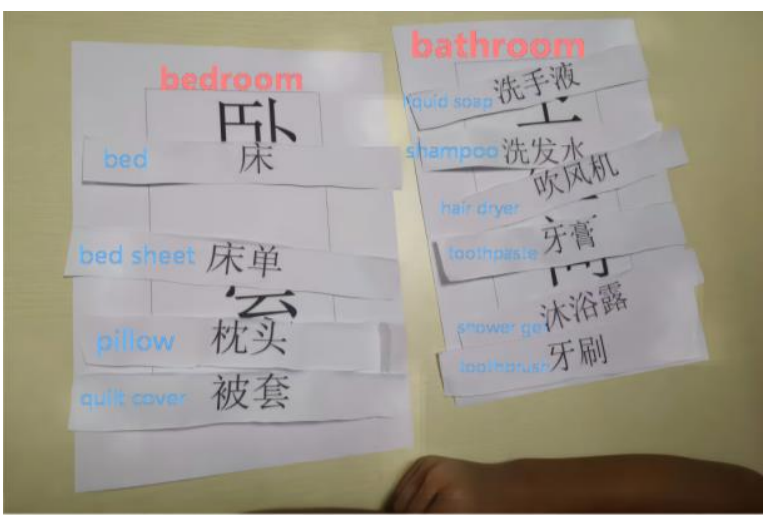

Figure 1. Game props

\section{ANALYSIS AND DISCUSSION}

In ancient Greek, there is only one word difference between "paidia" and "paideia", both of which are closely related to the growth of children [7]. According to the viewpoint of "all forms of play have the potential to result in all four types of engagement (affective, cognitive, behavioral, sociocultural)"[8], the educational significance of this game piece can be analysed and discussed from four dimensions: affective, cognition, behaviour and social culture.

\subsection{Affective}

The setting of this "Design Home Game" itself is in line with children's emotional needs. First of all, "home" is a word reminiscent of warmth and comfort, and "Design Home Game" provides children an opportunity to arrange their own home through simple paper placement, which is of great help to dispel their nervousness about entering the summer trusteeship class and increase their closeness with their peers. Secondly, in the term of motivation, the awards setting for winners motivate children to participate in games. What's more, the upsurge of group positive emotions creates a pleasant game atmosphere, which also greatly strengthens children's emotional motivation to participate in games. When children devote themselves to the game, they concentrate and once enter a state of "flow", and their hearts are filled with a sense of fullness and 
excitement. This kind of game process brings full emotional experience to children.

\subsection{Cognition}

According to embodied cognition theory, the learning process is a dynamic and unified process of cognition, body and environment [9]. This is particularly obvious in the "Design Home Game". In the process of playing games, children's cognitive development is the result of the interaction between the body and the environment composed of surrounding things and people in a proper way. In the process of interaction, the lower-grade children learned new words on the note by asking the upper-grade children and accurately classified the "items" represented by the note into the "room", and communicated with the team members about the placement of the other family's items. The cognitive development reflected by this physical movement of "placing a note" includes the increase of vocabulary and the accumulation of common sense, as well as the study of problem-solving strategies.

\subsection{Behaviour}

Games create a brand-new field for children. Under the restriction of the rules of the game, children are bound to give up the activities they usually enjoy and restrict their behaviour. "Raise your hand" before the start of "settling down" game is a special physical action, which can effectively prohibit children from doing behaviours that are contrary to the fairness of the game before the start of the game. Even so, there are still children who intentionally or unintentionally break the rules in order to win. In group activities, the violation of rules is not conducive to the game, and stopping directly will dampen people's positive emotions. Therefore, the host volunteer replaced the previous rule with a fairer one, thus effectively restraining children's violations. In addition, children who love video games and cartoons at daily times can significantly reduce the time spent facing the electronic screen, increase the physical activity time and protect their eyesight when participating in interactive games with real people. Physical myopia, obesity, psychological anxiety, autism, impulsivity and other health problems are more linked to "addiction to video games [10]. Live interactive games also have some therapeutic effects on video game addiction.

\subsection{Social Culture}

The first social culture conveyed by "Design Home Game" is the modern lifestyle. In the virtual game field, children recall the functions of various room areas in real life, discuss with their game companions the issue of household goods, and argue about the use scenarios of various modern electrical appliances. Children have experienced the actual modern lifestyle in their daily life, which is the basis for the game to go on. The "Design Home Game" is actually a process of strengthening, highlighting and supplementing children's induction and presentation of modern life cognition. It partly shows the process of children's socialization in their family life with adult parents.

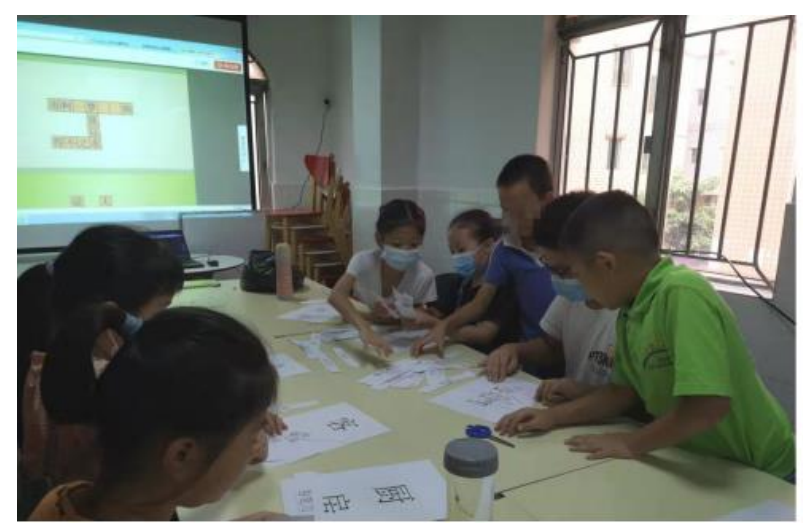

Figure 2. Game scene

The second social culture conveyed by "Design Home Game" is the mainstream values such as rules and fairness, cooperation and competition. If children want to win the game, they must abide the rules of the game and adapt to the game mechanism of cooperation within groups and competition among groups. Only when children are in a real interactive situation and feel other people's reactions to their behaviours can they get out of self - centred doctrine, realize their boundary relationship with others, feel the natural consequences of violating the rules and keeping the rules, then gradually form a sense of rules. The result of the game is a natural consequence, and the failure in the game can especially touch the nerve of reflection. As long as children are guided to review their personal performance and the performance of other group members, children will soon realize the key of the victory is cooperation. The game is competitive. In the group competition, children know more about the significance of cooperation and competition.

\section{CONCLUSION}

When playing games, people are fully engaged in the game, then they are completely human [11]. With the help of the Interaction Model of Learner Activity (Domagk et al., 2010) improved by Jan et al, this paper reveals the important influence of games in community summer childcare on children's affective, cognition, behaviour and social culture. The research shows that interactive game activities are beneficial to children's growth in emotional stimulation, understanding of the world, cultural learning and teamwork, etc. If the games are carefully designed and widely used in community summer care from these four dimensions, the trusteeship quality can be effectively improved. 


\section{ACKNOWLEDGMENT}

This work is supported in part by government-purchased projects of Pingshan Street Community Party-mass Service Centre and its sub-sites in Pingshan District (GJCG1810023F).

\section{REFERENCES}

[1] Volmut, T., Piot, R., Planinec, J., \& Imuni, B. Physical activity drops during summer holidays for 6- to 9-year-old children. Frontiers in Public Health (8), 1060-1066. (2021).

[2] Chen, X. Can campus trusteeship solve the "summer anxiety" of dual-employee families? Workers' Daily, (003). (2021, July 16).

[3] Xiao, Qing S. Thoughts on the urgent problems of summer trusteeship service. Tianjin Education (25),2123. (2021).

[4] M.Murray.et, "S.1360", in the conference 117th congress 1st session, Huashengdun, usa, april 22, 2021.

[5] Hu, Mo H. The Ministry of Education issued the Notice on Supporting the Exploration and Development of Summer Custody Service. Study abroad (14), 16. (2021).
[6] Domagk, S., Schwartz, R. N., \& Plass, J. L. Interactivity in multi-media learning: An integrated model. Computers in Human Behavior (26), 1024-1033. (2010).

[7] Wu, H. Games and Education-Also on the Gameness of Education. (Doctoral Dissertation, Central China Normal University). (2001).

[8] Plass, Jan L.; Homer, Bruce D.; Kinzer, Charles K. Foundations of Game-Based Learning. Educational Psychologist 50(4), 258-283. (2015).

[9] Li, Hai F. \&Wang, W. Research on educational game design based on embodied cognition theoryfrom the construction of EGEC framework to the development and application of "Sanitation Fighter" game. China Audio-visual Education (05),50-57. (2015).

[10] Jiang, H. and Shen, J. "Gaming Disorder" and Healthy Countermeasures-Adaptability of Health Communication in the Game. Journal of Beijing Institute of Technology (Social Science Edition) (1),157-163. (2020).

[11] Chen, Y. Game: The Wisdom of Relaxation (Doctoral Dissertation, Nanjing Normal University). (2003). 